\title{
Raman spectroscopy for the investigation of carbon-based black pigments
}

\author{
Alessia Coccato, ${ }^{a *}$ Jan Jehlicka, ${ }^{b}$ Luc Moens ${ }^{c}$ and Peter Vandenabeele ${ }^{a}$
}

\begin{abstract}
Raman spectroscopic studies of carbonaceous materials are, until now, mainly devoted to geological and industrial materials. On the other hand, it is known from artistic literature that many varieties of carbon-based black pigments were produced and used in different places and times, and according to the artist's preferences. The ability of Raman spectroscopy to analyse particles down to $1 \mu \mathrm{m}$ and its non-destructiveness make it an ideal tool for pigments investigation. Anyway, the discrimination among different types of carbon-based black pigments is affected by various aspects, one of which is the lack of reference spectra as well as of specific nomenclature. In this paper, reference materials have been studied by means of Raman spectroscopy to provide reference spectra. All the pigments showed two broad bands of carbon, but sometimes specific excitation conditions were required to record a good quality Raman spectrum. The obtained Raman signatures are discussed, on the basis of the specificities of the pigment (natural or artificial origin; structural implications related to the raw materials used or to production processes; etc.). Therefore, on the basis of the Raman spectra of painting materials, further knowledge can be obtained on the type of carbon-based black pigments in works of art. Copyright $\odot 2015$ John Wiley \& Sons, Ltd.
\end{abstract}

Keywords: Raman spectroscopy; carbon-based pigments; black pigments

\section{Introduction}

Carbonaceous matter can be found in nature as geological deposits of graphite and related materials, or can be produced by firing organic materials. The composition of carbonaceous matter from rocks can vary from pure carbon (graphite, diamond, lonsdaleite, chaoite and fullerene), through polymers (e.g.fossil resins and kerogen) to more or less liquid complex mixtures of hydrocarbons (e.g. petroleum and bitumens). These materials are widely distributed in sedimentary series throughout the world, originating from biota from different environments and of different ages of the Phanerozoic era. The use of carbonaceous matter is recorded in a variety of fields. Coal and petroleum have served as sources of energy and of derived chemicals for a long time. Natural geological carbonaceous compounds are also used as gemstones: jet is a fashionable carbonaceous matter derived from carbonification of wood-rich sediments from few sites of Jurassic age (UK, Asturias and Whitby); diamond is a rare transparent and hard phase used in jewellery. As a pigment or as a drawing material, in the field of cultural heritage, carbon-based materials play an extremely important role. Carbon materials, of mineral, vegetable or animal origin, composed ideally of pure carbon, were largely employed during prehistory ${ }^{[1-8]}$ and were never abandoned by artists and artisans. ${ }^{[9]}$ Carbon-based materials are suitable for both dry and liquid drawing (in the form of graphite, charcoal sticks, black chalk, pastels and inks, respectively ${ }^{[1]}$ ) and have been used as pigments for paintings, ${ }^{[2,5,10-18]}$ for polychrome objects ${ }^{[9,19]}$ and for pottery. ${ }^{[8,20]}$

The continuity of use through time and the worldwide distribution of this kind of materials require the establishment of a welldefined terminology that could be easily used for archaeometrical applications, but that keeps into account the major contributions of geological and industrial research to the study of carbon-based materials, along with the information from artistic literature (treatises $^{[1,21,22]}$ ).

The lack of archaeometrical literature on the specific topic of distinguishing among different carbon-based black pigments $\mathrm{s}^{[3,23]}$ made necessary a survey of geological and industrial literature, which indeed suggested some useful ideas for data processing and interpretation, while many aspects were not considered. This latter fact is mainly because of an important consideration, which is the non-correspondence between geological and artistic nomenclature. ${ }^{[24]}$

The scope of this paper is of offering a general terminology for archaeometrical purposes and of providing some indications for a better comprehension of carbon-based black pigments.

Non-carbonaceous black pigments are, for example, iron and/or manganese containing oxides/hydroxides with spinel structure, ${ }^{[8,15,20,25-27]}$ pure metals as powdered bismuth, ${ }^{[27-30]}$ black minerals as tenorite, ${ }^{[22]}$ enstatite, ${ }^{[22]}$ stibnite, ${ }^{[27]}$ galena ${ }^{[27]}$ and tourmaline, and other compounds of synthetic origin (copper nitrate derivative and hydrous molybdenum oxide $\left.{ }^{[22]}\right)$. All these

* Correspondence to: A. Coccato, Ghent University, Department of Archaeology, Sint-Pietersnieuwstraat 35, B-9000 Ghent, Belgium.

E-mail:Raman@ugent.be

a Ghent University, Department of Archaeology, Sint-Pietersnieuwstraat 35, Ghent B-9000, Belgium

b Charles University, Prague, Institute of Geochemistry, Mineralogy and Mineral Resources, Albertov 6, 128 43, Prague 2, Czech Republic

c Ghent University, Department of Analytical Chemistry, Krijgslaan 281, Ghent B9000, Belgium 
materials, except tourmaline, have been identified in archaeological and art historical manufacts.

\section{Carbonaceous materials' geological definitions and carbon-based black pigments}

Concerning the archaeometrical study of carbon-blacks, it is necessary to point out a fundamental issue, which is the simultaneous presence of different carbon types, according to geological definitions, in a specific carbon-based black pigment. ${ }^{[24]}$

Elementary carbon exists in one of its allotropic crystalline forms as graphite. More or less disordered materials occur, and comprehend flame carbons, cokes, chars and coals ${ }^{[24]}$ (see Table 1). Historical carbon-based pigments cannot be described properly using the previous categories, because they can contain some different substances (from a compositional or structural point of view).

For studying carbon-based black pigments a different classification is proposed ${ }^{[1,24]}$ which is based on the production processes: carbon-blacks of mineral origin, pigments from firing vegetable materials or from animal ones and pigments obtained in the form of soots and smokes. Still, some carbon-based pigments cannot be ascribed to any of these categories, as iron-gall inks and the black ink produced by Cephalopoda (Sepia black).

It is important to stress that the term 'carbon-black' is often used to encompass pigments, while 'black carbon' is used for particulate atmospheric residual carbonaceous matter sometimes deposited from atmosphere to soils.

\section{Raman spectroscopy on carbonaceous materials}

Common geological phases of carbon (e.g. graphite and diamond, as well as rare minerals chaoite and lonsdaleite) occur in nature as crystalline. Other carbonaceous compounds, generally not pure carbon, from rocks are frequently more or less amorphous. ${ }^{[33]}$ Bitumens, solid bitumens, resins and fossil resins as well as associated organic compounds in soils and rocks show always a lower structural organization than the ordered form of hexagonal carbon (i.e. graphite). Hence, Xray diffraction (XRD) or electron diffraction (ED) techniques are not suitable for analysis, unlike their primary role in analytical mineralogical studies. TEM represents a useful tool to recognize and visualize the heterogeneity of the samples and describe the so-called microtexture, i.e. mutual arrangement of structural units. ${ }^{[34]}$

Raman spectroscopy has played and continues to play an important role in the structural characterization of graphitic/ carbonaceous materials of different origin, ${ }^{[35,36]}$ as the spectrum is affected by the degree of crystallinity. This technique has been used to characterize graphitic materials (highly oriented pyrolytic graphite, carbon fibres, glass-like carbons ${ }^{[37]}$ ) and carbonaceous nanomaterials (fullerenes, and carbon nanotubes ${ }^{[38,39]}$ ). Raman spectroscopy has been found to be very sensitive to structural changes that modify translational symmetry in carbonaceous materials, thus being an ideal method for characterizing the carbonaceous matter structure. Careful Raman investigation of the carbonaceous matter of geological materials (metamorphic rocks, inclusions in magmatic rocks, dispersed carbonaceous matter) permits us to learn more about the structural order in carbonaceous matter and to obtain salient information on provenance. Because of the amorphous character of many sedimentary and even metamorphic carbons, as well as of carbons used frequently in fine arts artefacts, other appropriate techniques of characterization can be evoked, typically transmission electron microscopy (TEM). This method affords the visualization of basic structural units or molecular units and their orientation in space, but sampling is needed, which is rarely allowed for cultural heritage objects. It could be indeed very usefully combined with Raman spectroscopy.

Ordered graphite consists of arrangements of two-dimensional graphene sheets parallel oriented with carbon atoms being arranged in hexagonal rings through localized in-plane $2 \mathrm{~s}, 2 \mathrm{p}_{\mathrm{x}}$ and $2 p_{y}\left(s p^{2}\right)$ orbitals. The individual sheets are weakly bonded by delocalized out-of-plane $2 p_{z}$ orbitals, which overlap to give a delocalized electron system. ${ }^{[35]}$ All other carbons-disordered graphite, soot, 'carbon-black', 'lampblack' and the different forms of amorphous carbon-display less periodical structure (generally with only biperiodic arrangement of basic structural units, $\mathrm{BSU}){ }_{1}^{[36]}$ which modifies the structural order, and thus can be monitored in the Raman spectrum. A proper understanding of the disorder-related features in the Raman spectrum of carbon will certainly improve the chances of reconstructing the formation process of a certain carbon-based black material. Some ideas have been collected from geological literature and carefully transferred to the archaeometrical field of interest, always keeping into account that the experimental conditions of measurement (first, the laser wavelength) and the spectral processing vary.

The spectral region between 1000 and $1800 \mathrm{~cm}^{-1}$, the carbon first-order Raman spectrum, contains most of the structural information for carbonaceous materials. In hexagonal graphite a single band at $1582 \mathrm{~cm}^{-1}$ occurs and is assigned to the $\mathrm{G}$ band in-plane aromatic ring $C C$ stretching vibrational mode with $E_{2 g 2}$ symmetry. ${ }^{[40]}$ However, when disordered $\mathrm{sp}^{2}$ carbons are present, significant spectral modifications can be observed-the $G$ band

$$
\begin{aligned}
& \text { Table 1. Forms of carbon according to }{ }^{[24,31,32]} \text { and JJ } \\
& \text { Graphite } \\
& \text { Crystalline hexagonal form of carbon, of natural or artificial origin. d002=0.3356 nm, P63/mmc, different } \\
& \text { uses since prehistoric times up to today. } \\
& \text { Clame carbons/soots } \\
& \text { Chars } \\
& \text { Product of wood pyrolysis. Non-graphitizable carbons: the solid phase structure is maintained during } \\
& \text { carbonization. } \\
& \text { Man-made material and fuel produced by carbonization of bituminous coals or bitumen. Graphitizable } \\
& \text { carbons: the precursor is liquid/plastic immediately before carbonization. Cokes made from coal are } \\
& \text { highly porous. } \\
& \text { Organic rocks (lithified plant remains) composed of macerals (i.e. the equivalent of minerals for the } \\
& \text { inorganic rocks) that were formed during the Carboniferous Period. Initially unaltered sedimentary } \\
& \text { material containing plant remains change progressively (these changes include physical, biochemical } \\
& \text { and chemical processes) during diagenesis and catagenesis. Allochtonous materials are also present, } \\
& \text { as quartz and carbonates. }
\end{aligned}
$$


broadens and new bands arise-as a consequence of decreased order (crystallite size, presence of impurities, etc.) (Fig. 1). The socalled $D$ bands have been correlated with different causes of disorder. The $1355 \mathrm{~cm}^{-1}$ band (D1) has been first interpreted as particle size effect, as the $A_{1 g}$ mode becomes active because of finite crystal size. ${ }^{[40]}$ This band was also assigned to edge effect, plane defects and heteroatoms as oxygen or double bonds. Other impurities are considered responsible for this broad band. Vidano et al. ${ }^{[38]}$ observed the absence of this band in compression-annealed carbons, which was later suggested as an indicator of increasing degree of metamorphism. ${ }^{[42]}$ This band is also absent in highly ordered graphites. ${ }^{[4,45]}$ The D1 band position is found to cover the whole range 1240 to $1400 \mathrm{~cm}^{-1[46-50]}$ and it shifts with the used laser wavelength. ${ }^{[45,49,51]}$ Its intensity depends on the carbon type, ${ }^{[37]}$ on the amount of disorder, ${ }^{[40]}$ on the orientation of the crystal with respect to the laser ${ }^{[52]}$ and on the measurement conditions.

The D2 band at ca. $1600 \mathrm{~cm}^{-1}$ is assigned to the splitting of the degenerated $E_{2 g}$ vibration. ${ }^{[37,38]}$ This band is expected whenever the D1 band is present. ${ }^{[53]}$ The G and D2 band positions overlap, creating a more or less symmetric feature in the Raman spectrum of disordered carbons. This band appears (and its intensity increases) in disordered materials, but it is found to be resolvable from the $\mathrm{G}$ band in ordered ones. ${ }^{[52]}$ The D3 band position shifts from 1440 to $1550 \mathrm{~cm}^{-1}$. Its assignment is still debated, but it suggests the presence of disorder both as structural defects ${ }^{[54-56]}$ and impurities. ${ }^{[33,51,57]}$ The fourth disorder band of carbon, D4, has the lower wavenumber. It is found below $1290 \mathrm{~cm}^{-1}$ so that it appears mainly as a shoulder on the D1 band. ${ }^{[58]}$ It is observed in extremely disordered materials, ${ }^{[43]}$ as bitumens, ${ }^{[52]}$ soots $^{[51,33]}$ and wood charcoal. ${ }^{[59,60,59]}$ Care has to be taken to avoid spectral artefacts as a consequence of inappropriate band fitting. ${ }^{[57]}$

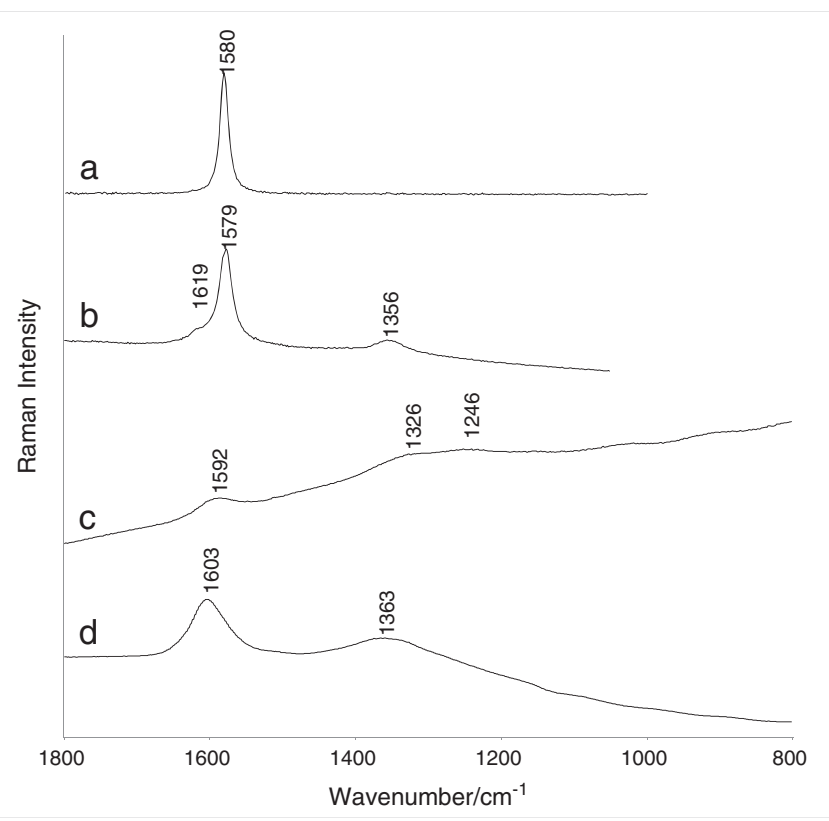

Figure 1. a) Ordered graphite, b) graphite from metamorphic rocks, c) black earth, 785-nm laser, $4 \mathrm{~mW}, 30 \times 10 \mathrm{~s}$, d) black earth 532-nm laser, $1.45 \mathrm{~mW}, 50 \times 10 \mathrm{~s}$. The selected spectra show some examples of carbonaceous material Raman spectra. Different measurement conditions were required to obtain those signatures, which correspond to ordered structures ( $a$ and $b$, graphites), and to less ordered materials ( $c$ and $d$, black earth). Also, the effect of the laser wavelength on the band positions and relative intensities is visible in black earth Raman spectra (c and d).
To complete the overview of carbon bands, we also mention the one of diamond $\left(1332 \mathrm{~cm}^{-1},{ }^{[57]}\right)$, those of fullerenes (1459-1469 and $\left.930-970 \mathrm{~cm}^{-1},{ }^{[38]}\right)$ and rhombohedral graphite $\left(1400 \mathrm{~cm}^{-1[49]}\right)$, as summarized by Table 3 .

\section{Production and use of carbon-based black pigments}

Amorphous carbon as a pigment was identified in prehistoric sites worldwide (e.g. Ekain cave, Basque country, $16500-12500 \mathrm{BP}_{,}^{[5]}$ ancestral Puebloan artefacts, 1000-1200 AD ${ }^{[15]}$ ), in dynastic Egyptian manufacts, ${ }^{[19]}$ in Greek-Roman remains throughout Europe. ${ }^{[1,16]}$ Some raw materials (crayons from prehistoric sites and paint pots from Pompei) have also been investigated. ${ }^{[16]}$ Pliny the Elder ${ }^{[62]}$ is probably the oldest source mentioning the use of carbon-based black pigments, while we have plenty of medieval artistic literature describing in detail the preparation of various pigments and polychromic artefacts (paintings, statues, ceramics...). The written recipes, anyway, are difficult to correlate with specific materials. This is related to the variety of used materials and to the problematic identification of materials on the basis of traditional names. Moreover, the empirical needs of painters and artisans, as regards obtaining specific colour shades or paint texture, certainly had an influence on the traditional recipe, which was adjusted accordingly. Furthermore, different treatises use different terms as synonyms, while sometimes it is also possible that the same material has completely different names, or that spelling issues may lead to misidentification of materials. ${ }^{[1,22]}$ Artists' materials suppliers, who produce pigments according to ancient recipes, are also to be considered in this field of study, because they play an important role in restoration processes. Pigments currently produced, even following old treatises, may have different characteristics with respect to the old ones because of technical aspects of the process (temperature control, anaerobicity, etc.) or to the used raw materials. It is also important to mention the existing (and also potential) confusion in terminology in recipes coming from artistic literature itself and from correlating it with scientific papers.

\section{Focal points}

The previous paragraphs highlight a number of issues relating to Raman spectroscopy of carbonaceous materials in archaeology:

- inhomogeneity and general inconsistence in the naming of carbonaceous matter in literature: terminological discrepancies exist among archaeologists/art historians, chemists/ physicists/spectroscopist and geologists; pigment names may have not been constant through time and space; commercial pigments may not necessarily correspond to what expected;;63]

- no general agreement on the origin of the so-called disorder $D$ bands;

- Raman bands shift because of intrinsic characteristics of the materials and measurement setup (orientational effects, wavelength dependent band shift and intensity, etc.), band overlap.

\section{Experimental}

Reference black pigments were selected among Kremer Pigmente (Aichstetten, Germany) productions. Care was taken in purchasing pigments that have a historical use (i.e. have been already identified in works of art) or that have been described in artistic literature. ${ }^{[1,22]}$ 
In addition to these pigments, ordered graphite and graphite from metamorphic rocks were analyzed for comparison.

A list of the studied pigments, their composition as declared by the producer, as well as some additional information as regards different ways of classifying carbonaceous black pigments are given in Table 2. Also, the laser used for obtaining the spectra is there noted.

The Raman spectrometer used is a Bruker Optics 'Senterra' dispersive Raman spectrometer with a BX51 microscope. The instrument is equipped with 532 (Nd:YAG) and 785-nm (diode) laser sources. High-resolution $\left(3-5 \mathrm{~cm}^{-1}\right)$ spectra are recorded in the range of $60-2750 \mathrm{~cm}^{-1}$ and $80-2640 \mathrm{~cm}^{-1}$ for the 532 and $785-$ $\mathrm{nm}$ lasers, respectively. The system uses a thermo-electrically cooled CCD detector, operating at $-65^{\circ} \mathrm{C}$. The power of each laser is controlled via software in discrete steps. For the red laser, powers of ca. 4 and $15 \mathrm{~mW}$ were used; the green laser was operated mainly at $1.4 \mathrm{~mW}$. The $20 \times$ objective was used for all the samples, with a spot size of approximately $10 \mu \mathrm{m}$. The microscope contains a joystick-controlled motorized stage, and the analysed area is displayed on screen with the aid of an attached video-camera. The instrument is controlled via the OPUS software.

At least three spectra per sample were acquired. Both lasers were used in order to achieve good quality Raman spectra: the red laser was used first to test all the pigments, starting with the lowest achievable laser power. If no spectra could be recorded (flat spectrum or just fluorescence), first the laser power was increased and then the number of accumulations adjusted. Different laser powers were used in order to obtain good quality spectra, while keeping the integration time constant ( 10 seconds). The number of accumulations varied from 10 to 300 to improve the signal to noise ratio. The laser power on the sample was selected case by case, to maximize the scattering while minimizing potential damage to the pigment itself and acquisition time. The reason for preferring the 785-nm excitation line is in its suitability for the study of many historically used pigments and for some geological applications. ${ }^{[46]}$ It is also known that the shorter the laser wavelength, the higher is the fluorescence background. However, for geological carbon studies the most used wavelengths are in the green region of the visible spectrum. The green $(532 \mathrm{~nm})$ laser sometimes made the acquisition possible for those samples that shown no bands with the 785-nm excitation; on the other hand it sometimes increased the fluorescence signal so that the carbon bands were then not recognizable at all. The variety and complexity of the studied materials made necessary this inhomogeneous approach. The excitation wavelength will be always specified in the results presentation and discussion section.

The subsequent data processing was homogeneous for all the spectra. First, a linear baseline was subtracted in the range ca. 800 to ca. $1850 \mathrm{~cm}^{-1}$, then the spectra were deconvoluted in GRAMS 8.0 using Lorentzian shaped curves for the carbon bands, and Gaussians (for example for fitting the valley between the $D$ and $G$ bands). The values obtained through this deconvolution procedure (position, width, intensity and area of the bands) were collected in an Excel sheet. These values were compared with the literature, but the identification of the expected $G$ and $D$ bands was not straightforward, especially as regards D1. This band (see Table 3) proved to be the most difficult to identify, because of the presence of multiple bands in the range where D1 can be found. This made the calculation of ratios, such as R1 and $\mathrm{R} 2,{ }^{[43]}$ which are related to the structural order of carbonaceous matter, unfeasible. As these ratios could not be calculated with sufficient reliability, they were not considered further. The spectrum as a whole was also considered, for identifying mineral impurities and additional features.
Total-reflection XRF analyses (TX2000 by GNR, Italy) were carried out only for qualitative purposes on selected pigments samples, to obtain more information on the chemical composition of carbonbased black pigments (characteristic impurities). The spectra were acquired for $1000 \mathrm{~s}$ (live time), using a Mo anode (40 kV, $30 \mathrm{~mA}$ ).

\section{Results and discussion}

The studied carbonaceous materials and carbon-based black pigments cover different grades of crystallinity, graphite corresponding to the highest order in the group, but at the same time represent the different forms of carbon listed in. ${ }^{[24]}$ In addition to Winter's classification, ${ }^{[24]}$ it is also possible to consider the origin of the pigments, as both natural and artificial materials have been used as black pigments. Among natural materials are listed minerals and organic matter that are used as they are as black pigments, as for example graphite, humic earths and sepia. For artificial black pigments, i.e. products of carbonization, it is important to consider the starting materials, so we can have carbon from vegetable, animal and mineral raw materials (Table 2). According to the characteristics of the starting materials (graphitizable vs nongraphitizable carbons ${ }^{[24]}$, the resulting product will show a more or less organized crystalline structure. Berrie, in, ${ }^{[1]}$ uses a slightly different classification for the 'practical pigments' (graphitic, soots and smokes, vegetable origin pigments, animal origin pigments, coals and related materials, pp. 1-38 $\left.8^{[1]}\right)$. A separate chapter in the book is dedicated to asphalt (pp. 111-150 $0^{[1]}$ ).

As expected, all the pigment samples showed, more or less intense, the two broad features typical of carbon, as shown in Fig. 1 (a spectrum of ordered graphite is given for comparison). It is known that disorder, in addition to a broadening of the Raman features, causes an increase in the number of Raman active bands. ${ }^{[72]}$

In many cases, the red excitation allowed the recording of a good quality spectrum (graphite, Fig. 2), but for most samples, both lasers were tested, because no clear results were given with the 785-nm diode laser excitation: sometimes the quality of the spectrum was much improved when using the green excitation (black chalk, Fig. 1), while in some other cases, as for bituminous coals, only the green excitation allowed the recording of Raman bands instead of just fluorescence. Also, in some cases, the attempt to obtain a higher signal to background ratio by switching from the red to the green laser (as the green is preferred in geological studies) did not help in improving the signal, so that the considered spectra are those obtained with the 785-nm laser. Table 2 summarizes the excitation conditions.

The $G$ band, which is always clearly identifiable, is univocally assigned to ordered carbons' $E_{2 g}$ modes and is considered a marker for crystalline graphite. It broadens with increasing disorder. ${ }^{[71]}$ The D2 band arises in disordered carbons, at ca. $1600-1635 \mathrm{~cm}^{-1}$ (therefore overlapping with the $\mathrm{G}$ band, Table 3 ) and is associated also with the D1 feature, which means that all the studied pigments samples have a D2 band component, because they all show disorder bands between 1300 and $1400 \mathrm{~cm}^{-1}$. In the following, for disordered carbons we will name the $E_{2 g}$ mode as band $G^{*}$, if the D2 component is not resolvable, while band $\mathrm{G}$ will identify the ordered lattice vibration, without D2 disorder contribution.

\section{Graphite and crystalline carbons}

The producer's description of graphite pigment suggests an artificial origin for the material, according to the presence of ashes 


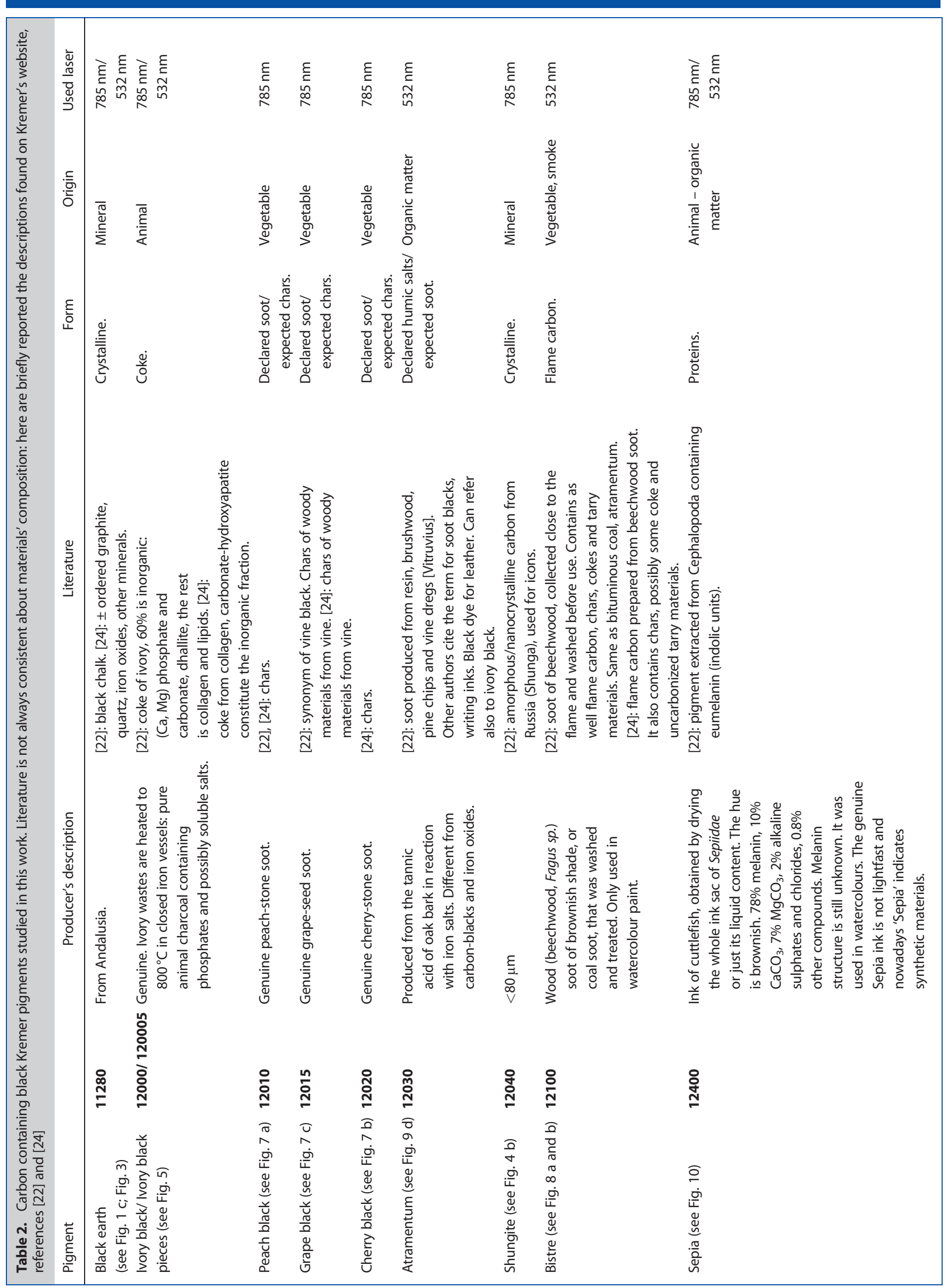




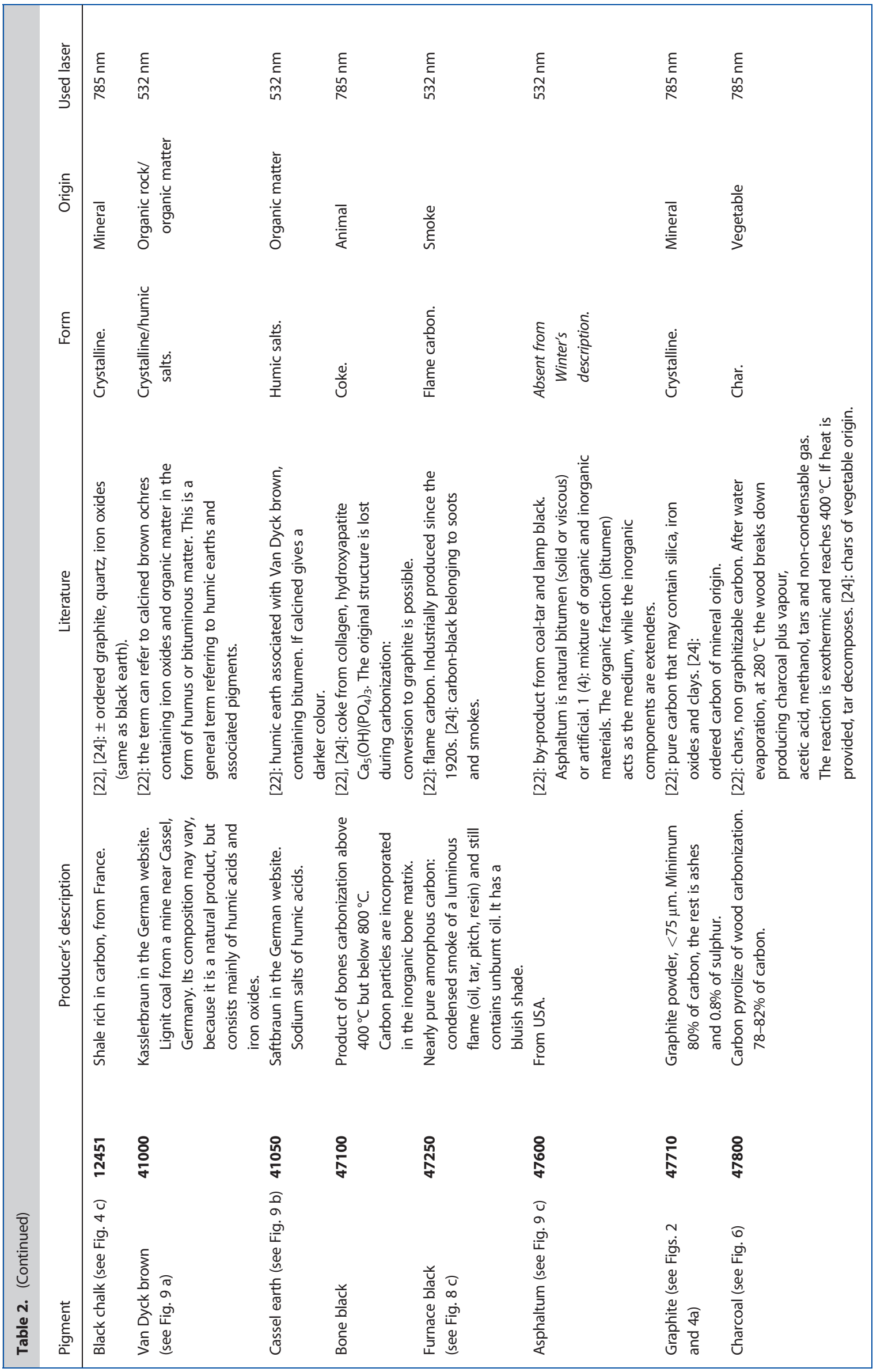


Table 3. Raman bands of carbonaceous materials

\begin{tabular}{|c|c|c|c|}
\hline Band & $\begin{array}{l}\text { Other band } \\
\text { symbols }\end{array}$ & Assignment & Position $\left(\mathrm{cm}^{-1}\right)$ \\
\hline G & G1 & $E_{2 g 2}, E_{2 g}$ & From $1550^{[49]}$ to $1620^{[44]}$ \\
\hline D1 & $\mathrm{D}$ & $\begin{array}{l}\mathrm{A}_{1 \mathrm{~g}}{ }^{[40,53,56]} ; \text { edge effects as oxides or } \mathrm{C}=\mathrm{C} \text { bonds }{ }^{[37,51]} ; \\
\text { in plane defects and heteroatoms }{ }^{[43,45,54,64]} ; \mathrm{sp}^{3}-\mathrm{sp}^{2} \\
\text { carbon bonds }{ }^{[8]} ; \text { volatile compounds, polyenes and } \\
\text { ions }{ }^{[33]}\end{array}$ & $\begin{array}{l}\text { From } 1301 \text { to } 1317 \text { (for a NIR/IR excitation }{ }^{[47,51,58]} \text { ) } \\
\text { to } 1390^{[49]}\end{array}$ \\
\hline D2 & $D^{\prime}, \mathrm{G} 2$ & $\begin{array}{l}\mathrm{E}_{2 \mathrm{~g}}^{\prime} \text { or } \mathrm{E}_{2 \mathrm{~g}} \text { or oxidized } \mathrm{sp}^{2} \text { carbons }{ }^{[37]} \text {; non } \\
\text { sandwiched graphene layers }{ }^{[51]} \text {; defects } \\
\text { as imperfect graphite or disordered } \\
\mathrm{E}_{2 \mathrm{~g}}{ }^{[3,45,53,64]} \text {; splitting of degenerated } \mathrm{E}_{2 \mathrm{~g}}{ }^{[41]} ; \mathrm{E}_{1 \mathrm{u}}{ }^{[56]}\end{array}$ & $\begin{array}{l}\text { From } 1599^{[51]} \\
\text { to } 1635^{[15,16,33,37,38,43,45,50,53-56,64-69]}\end{array}$ \\
\hline D3 & $D^{\prime \prime}, A$ & $\begin{array}{l}\text { Tetrahedral carbons (defects outside the carbon plane) }{ }^{[54]} \text {; } \\
\text { organic molecules, fragments and functional groups } \\
\text { of soot }{ }^{[51]} ; \text { oxygen on the surface of graphite }{ }^{[50]} ; \text { sp }^{2} \\
\text { carbons }^{[49]} ; \text { interstitial defects }{ }^{[55,70]} ; \text { amorphous } \\
\text { carbons }^{[45,56]} ; \text { methylene group vibrations }{ }^{[33]} ; v_{3} \text { of trans } \\
\text { polyenic molecules }\end{array}$ & From $1440^{[48]}$ to $1550^{[53][33,45-47,49,51,54-58]}$ \\
\hline D4 & I & $\begin{array}{l}\text { Defects }{ }^{[43,52,54]} ; \text { soot features, }{ }^{[33,51,56]} \text { like mixed } \mathrm{sp}^{2}-\mathrm{sp}^{3} \\
\text { bonds or polyenic structures }{ }^{[45,47,58]} ; \text { char and coal tar }{ }^{[48]} ; \\
\text { diamondlike carbon in anthracite }{ }^{[71]} ; \mathrm{sp}^{3} \text { carbons }^{[59,72]} ; \\
\text { nanocrystalline diamond or trans polyene } v_{1}{ }^{[57]} ; \text { defects } \\
\text { related to oxygen rich precursors as wood }{ }^{[60,61]}\end{array}$ & $\begin{array}{l}\text { From } 1050 \text { with deep UV excitation }{ }^{[57]} \\
\text { to } 1127^{[51]} \text { to } 1275^{[48][23,33,45,47,52-61,71,72]}\end{array}$ \\
\hline Fullerenes & & Phototransformation/oxidation ${ }^{[38,73]}$ & $1459-1469$ and $930-970^{[38,73]}$ \\
\hline $\begin{array}{l}\text { Rhombohedral } \\
\text { graphite }\end{array}$ & & $\mathrm{B}_{2 \mathrm{~g}}^{2}$ & $1400^{[48]} ;{ }^{[49]}$ \\
\hline
\end{tabular}

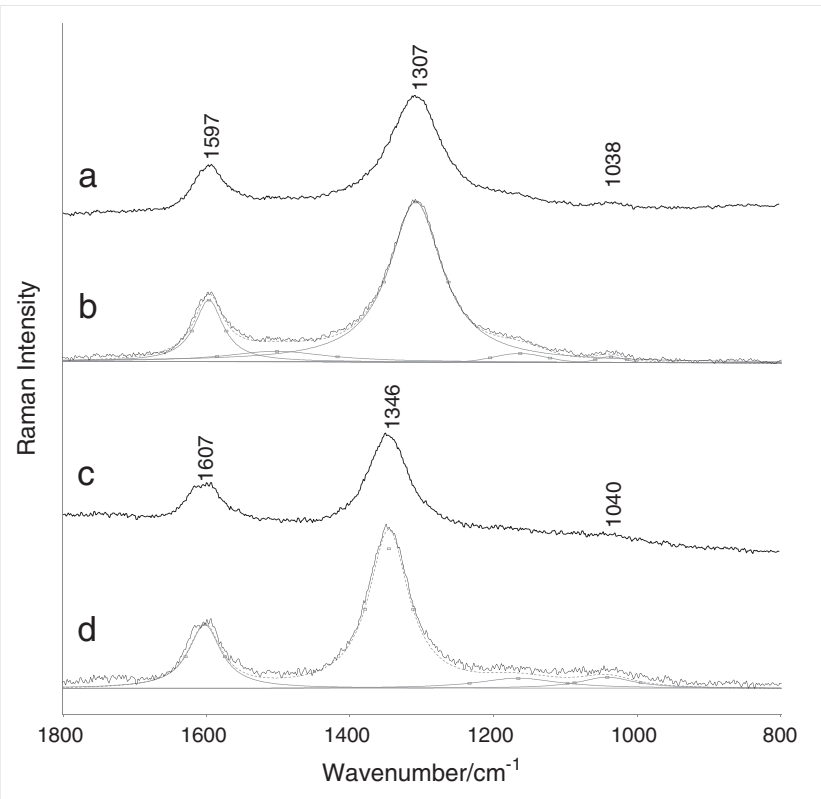

Figure 2. Raman spectra of graphite pigment, obtained with different laser wavelengths. A) graphite pigment $785-\mathrm{nm}$ laser, $7.4 \mathrm{~mW}, 40 \times 10 \mathrm{~s}$, b) graphite pigment (baseline corrected, with deconvolution) 785-nm laser, $7.4 \mathrm{~mW}, 40 \times 10 \mathrm{~s}, \mathrm{c})$ graphite pigment $532-\mathrm{nm}$ laser, $1.4 \mathrm{~mW}, 40 \times 10 \mathrm{~s}$ and d) graphite pigment (baseline corrected, with deconvolution) $532-\mathrm{nm}$ laser, $1.4 \mathrm{~mW}, 40 \times 10 \mathrm{~s}$.

(Table 2). Both lasers were tested for excitation (Fig. 2). The spectra show two broad bands after baseline correction: the $\mathrm{G}^{*}$ band is at $1593 \mathrm{~cm}^{-1}$ and the D1 at $1308 \mathrm{~cm}^{-1}$ with $785-\mathrm{nm}$ excitation and at $1596 \mathrm{~cm}^{-1}\left(\mathrm{G}^{*}\right)$ and 1346 (D1) $\mathrm{cm}^{-1}$ for the $532-\mathrm{nm}$ laser. The presence of the D1 band suggests that this pigment is a disordered graphite. No additional disorder bands were needed for the deconvolution of the green excited spectrum, but as explained above, and as indicated by the use of the $\mathrm{G}^{*}$ symbolism, the D2 band has to be considered present. The red excited spectrum required the D3 band to fit the valley between the G and D1 bands (Fig. 2). The weak band at ca. $1165 \mathrm{~cm}^{-1}$ could be identified as the D4 band.

Effects of mechanical sample alteration, differences between the orientation of graphitic crystallites or platelettes can be the origin of slightly different ratios of $G$ and $D$ bands. Especially the wavenumbers can be used for practical comparative purposes.

From Fig. 2, it is also clear the effect of excitation wavelength on the disorder band position, which is ca. $40 \mathrm{~cm}^{-1}$ downshifted for the diode laser. Moreover, both excitations produced a broad (ca. $50 \mathrm{~cm}^{-1}$ ) low wavenumber feature at ca. $1040 \mathrm{~cm}^{-1}$. The assignment of this feature is still unknown. A much lower fluorescence background for the lower frequency laser is also noticeable.

The pigment black earth was also tested with both lasers (Fig. 3). The spectra obtained with the green excitation were clearer than the ones collected with the red laser (cfr. Fig. 1): the higher signal to background ratio allowed the identification of other phases in addition to carbon. The two carbon bands maxima after baseline correction are 1592 and $1325 \mathrm{~cm}^{-1}$ and 1605 and $1352 \mathrm{~cm}^{-1}$, for the red and green laser, respectively. The detected mineral impurities are calcite (narrow band at $1088 \mathrm{~cm}^{-1[74,75]}$ ), quartz $\left(463 \mathrm{~cm}^{-1[74,75]}\right)$ and possibly anatase $\left(145 \mathrm{~cm}^{-1[75,76]}\right)$. A weak broad band was observed at ca. $1043 \mathrm{~cm}^{-1}$ for the $785-\mathrm{nm}$ excited spectrum, and at ca. $1082 \mathrm{~cm}^{-1}$ for the $532-\mathrm{nm}$ one.

Shungite (Fig. 4) proved to be very similar to graphite as regards to band positions $\left(G^{*}, D 1\right)$ and eventually showed a lower fluorescence background when single particles were measured, instead 

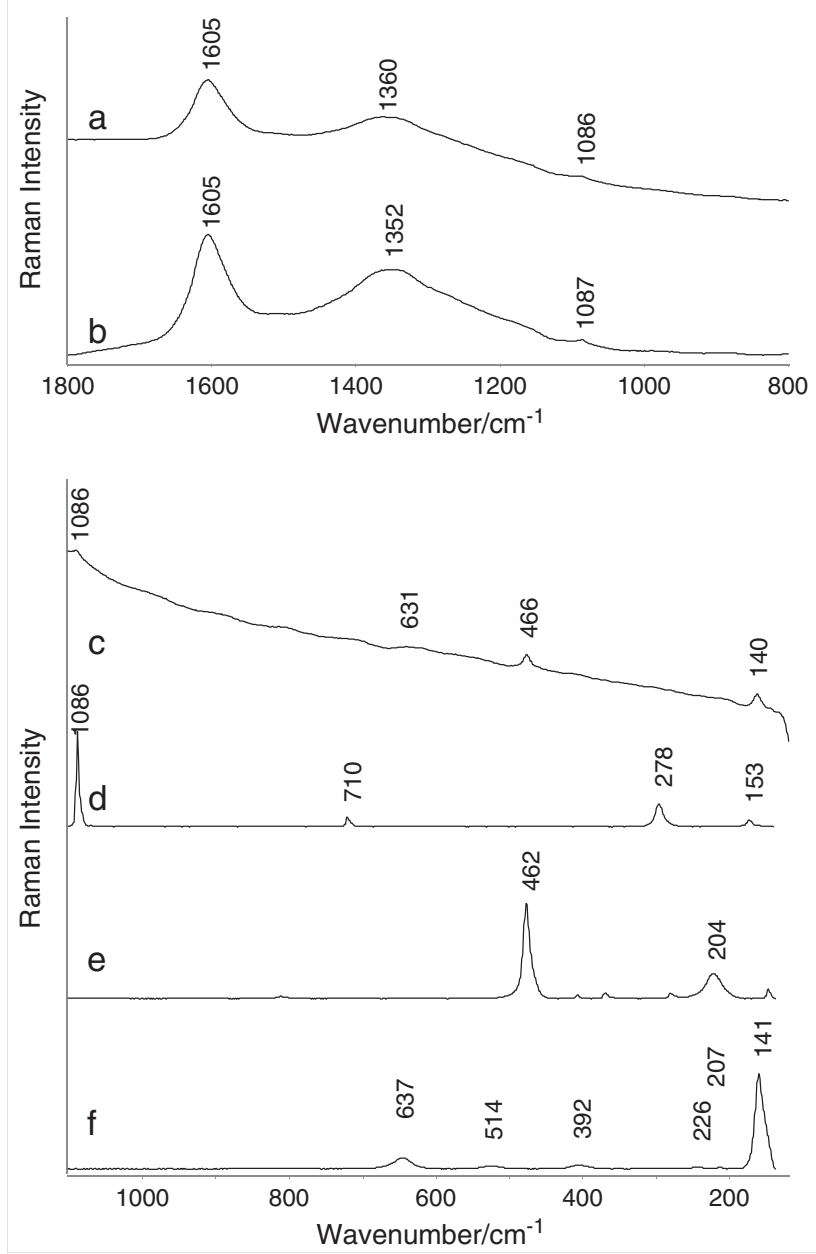

Figure 3. Raman spectrum of black earth pigment. a) black earth 532-nm laser, $1.4 \mathrm{~mW}, 50 \times 10 \mathrm{~s}$, b) black earth (baseline corrected) 532-nm laser, $1.4 \mathrm{~mW}, 50 \times 10 \mathrm{~s}$, c) black earth $532-\mathrm{nm}$ laser, $1.4 \mathrm{~mW}, 50 \times 10 \mathrm{~s}$, (zoom in), d) calcite R050009 (RRUFF database), e) quartz R050125 (RRUFF database) and f) anatase R070582 (RRUFF database).

of the fine powder. However, the structure of shungite is far from that of graphite. Calcite was detected (bands at 154 and $\left.281 \mathrm{~cm}^{-1},[75,76]\right)$, as well as quartz $\left(460 \mathrm{~cm}^{-1},[75,76]\right)$. The spectra recorded on finely powdered shungite show a very intense background, and broader $\mathrm{G}$ band with respect to the spectra recorded on a single particle, which resemble very closely the spectra of the pigment graphite.

Black chalk is usually considered as a synonym of black earth. The pigment black chalk was measured with the red laser. The two broad bands maxima are at 1600 and $1316 \mathrm{~cm}^{-1}$, with hardly resolvable G and D2 bands, respectively, at 1592 and $1610 \mathrm{~cm}^{-1}$. The fluorescence background was extremely low, similarly to the pigment black earth. No additional bands were needed towards the lower wavenumber region of the linearly baseline corrected spectrum (Fig. 4).

Ordered carbons can be easily excited with both the 785-nm (Fig. 4) and the 532-nm lasers (Fig. 3) and show a relatively narrow $G$ band $\left(51 \pm 3 \mathrm{~cm}^{-1}\right)$. The D1 band is weak, and, if present, it points out the presence of the D2 band, more or less overlapping with the $E_{2 g}$ mode. Care has to be taken as the $G$ band position, width and area can be strongly affected by this unresolvable feature.

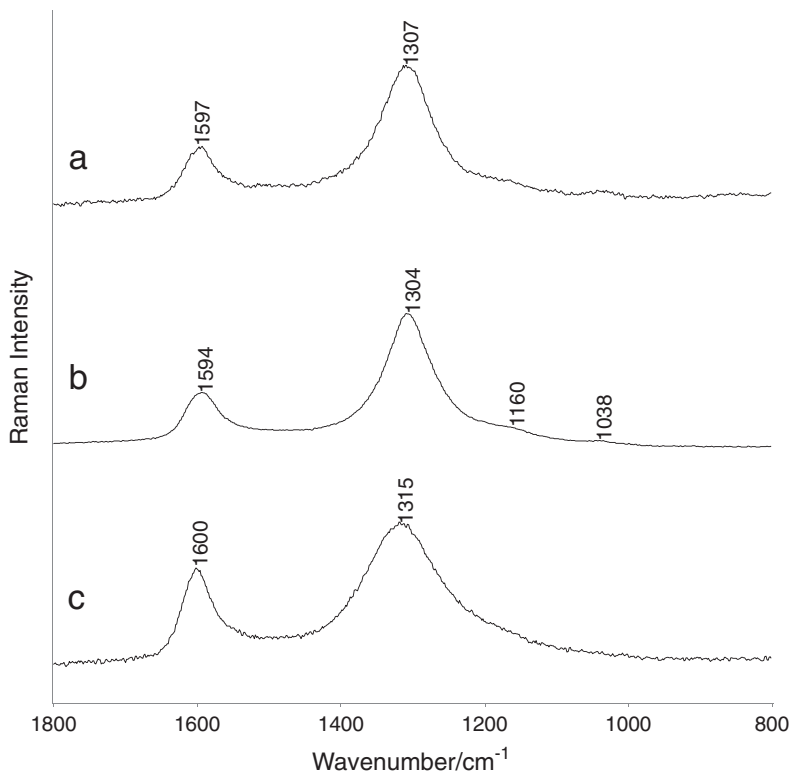

Figure 4. Ordered carbon Raman spectra collected with the red laser: a) graphite $785-\mathrm{nm}$ laser, $7.4 \mathrm{~mW}, 40 \times 10 \mathrm{~s}$, b) shungite $785-\mathrm{nm}$ laser, $15 \mathrm{~mW}$, $40 \times 10 \mathrm{~s}$ and c) black chalk $785-\mathrm{nm}$ laser, $4 \mathrm{~mW}, 30 \times 10 \mathrm{~s}$.

\section{Cokes}

As regards graphitizable carbons (cokes), two materials were available in three different forms: ivory black (powder and pieces) and bone black powder (Fig. 5). The distinction between bone/ivory black and other carbon-based black pigments is normally feasible by means of Raman spectroscopy thanks to the presence of a band at ca. $960 \mathrm{~cm}^{-1}$ (phosphate stretching ${ }^{[9]}$ ). This is expected on the basis of the composition of bone material (collagen and hydroxyapatite $\left.\mathrm{Ca}_{5}(\mathrm{OH})\left(\mathrm{PO}_{4}\right)_{3}\right)$. This band intensity varies in comparison to the carbon bands, but has been successfully identified. ${ }^{[9,77-80]}$

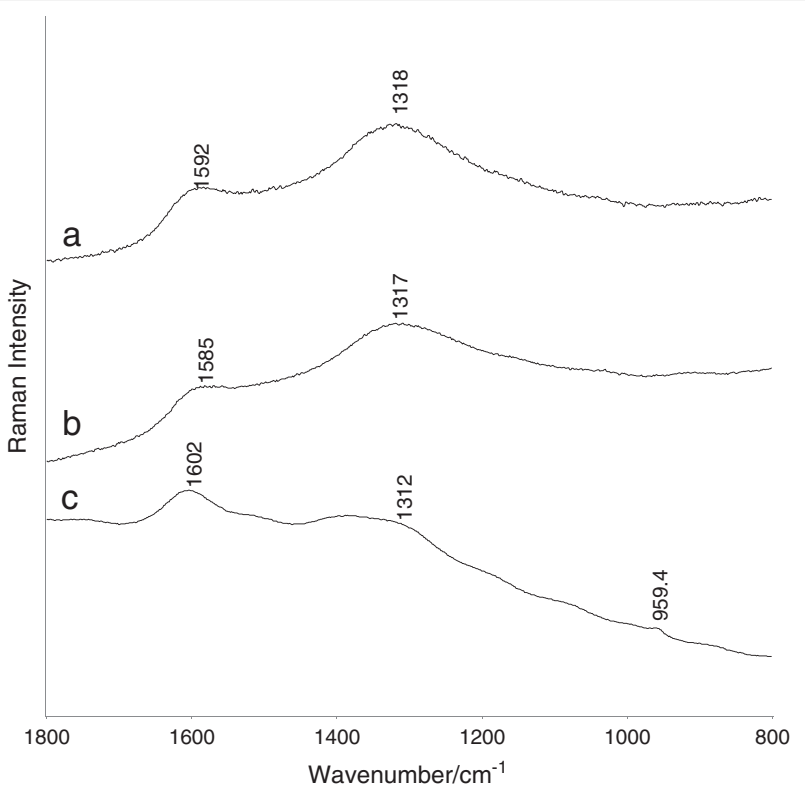

Figure 5. Raman spectra of coke pigments: a) ivory black pieces $785-\mathrm{nm}$ laser, $4 \mathrm{~mW}, 30 \times 10 \mathrm{~s}, \mathrm{~b}$ ) ivory black $785-\mathrm{nm}$ laser, $4 \mathrm{~mW}, 30 \times 10 \mathrm{~s}$ and c) ivory black 532-nm laser, $1.4 \mathrm{~mW}, 80 \times 10 \mathrm{~s}$. 
Among the studied materials, different animal blacks were available, as powder or as pieces (Fig. 5). First, ivory black powder and pieces require completely different measurement conditions in order to achieve good quality Raman spectra, respectively, 785-nm excitation (Fig. 5, spectra a and b) and 532-nm (Fig. 5, spectrum c). Moreover, the phosphate band was clearly identifiable only in powdered ivory black measured with the green laser (band at $961 \mathrm{~cm}^{-1}$, Fig. 5, spectrum c). Samples measured with the red laser did not show this band. The pigment bone black was measured with the red laser and no phosphate band was detectable either. It is known that it is sometimes difficult to detect the phosphate signal, ${ }^{[9,74]}$ and it seems that the negative criterion normally used for the identification of vegetable origin carbon black might be questionable, at least when using the $785-\mathrm{nm}$ laser. ${ }^{[80-82]} \mathrm{A}$ shoulder on the broad, asymmetric $D$ band is visible around $1040 \mathrm{~cm}^{-1}$. The results of TXRF analysis on powdered ivory black showed the presence of calcium and phosphorus, which confirms the Raman identification (with 532-nm excitation) of a black pigment of animal origin.

For cokes, either laser could be used. In the case of carbon-based black pigments, cokes are identified by the presence of the phosphate band, as bone material gives rise to graphitizable carbons. Anyway, the band at ca. $960 \mathrm{~cm}^{-1}$ is not always detected, so additional analyses are suggested for confirmation.

\section{Chars}

The only available sample of char-type carbon is pyrolized beech (Fagus sylvatica) charcoal. Good quality spectra were obtained with the red laser. A $G^{*}$ band (Fig. 6) and the other carbon disorder bands (D1 to D4) are all present and in good agreement with literature (D1: $1345 \mathrm{~cm}^{-1}, \mathrm{D} 3: 1510 \mathrm{~cm}^{-1}, \mathrm{D} 4: 1280 \mathrm{~cm}^{-1}$ ), but two more bands were required to obtain a good fitting. One is a band at ca. $1310 \mathrm{~cm}^{-1}$, and the other is at ca. $1031 \mathrm{~cm}^{-1}$.

The need for many bands to completely fit the spectrum suggests a high degree of disorder, which is the case for nongraphitizable carbons, as chars.

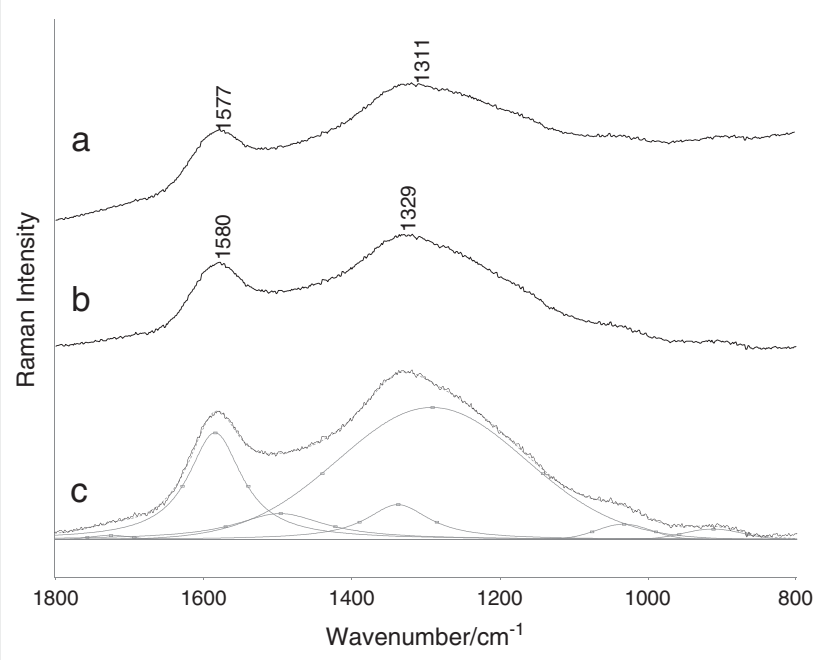

Figure 6. Raman spectra of charcoal. a) Wood charcoal 785-nm laser, $15 \mathrm{~mW}, 40 \times 10 \mathrm{~s}, \mathrm{~b}$ ) wood charcoal (baseline correction) 785-nm laser, $15 \mathrm{~mW}, 40 \times 10 \mathrm{~s}$ and c) wood charcoal (baseline correction, with deconvolution) $785-\mathrm{nm}$ laser, $15 \mathrm{~mW}, 40 \times 10 \mathrm{~s}$.

\section{Smokes}

A variety of soot materials were available for analysis, as various fruitstone soots (genuine peach, grape and cherry stones soot) and furnace black. Also, the pigment bistre is washed and treated beechwood (Fagus sp.) soot.

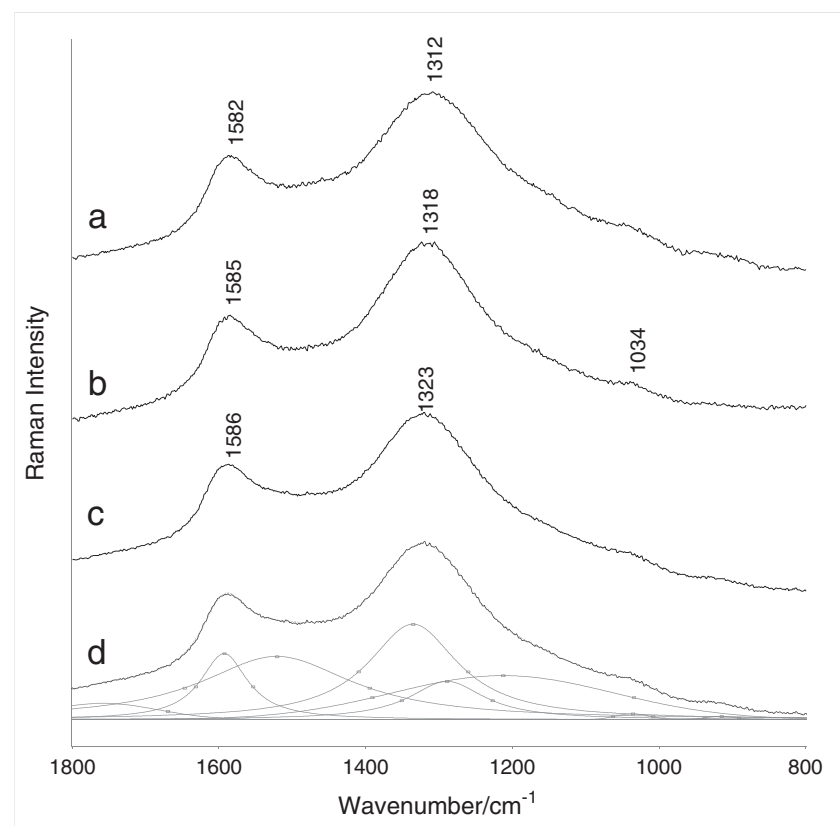

Figure 7. Flame carbons: fruitstone soot Raman spectra, collected with the red laser: a) peach black $785-\mathrm{nm}$ laser, $15.4 \mathrm{~mW}, 35 \times 10 \mathrm{~s}$, b) cherry black 785 -nm laser, $15.4 \mathrm{~mW}, 40 \times 10 \mathrm{~s}, \mathrm{c})$ grape black $785-\mathrm{nm}$ laser, $15.4 \mathrm{~mW}$, $20 \times 20 \mathrm{~s}$ and d) grape black (baseline corrected, with deconvolution) 785$\mathrm{nm}$ laser, $15.4 \mathrm{~mW}, 20 \times 20 \mathrm{~s}$.

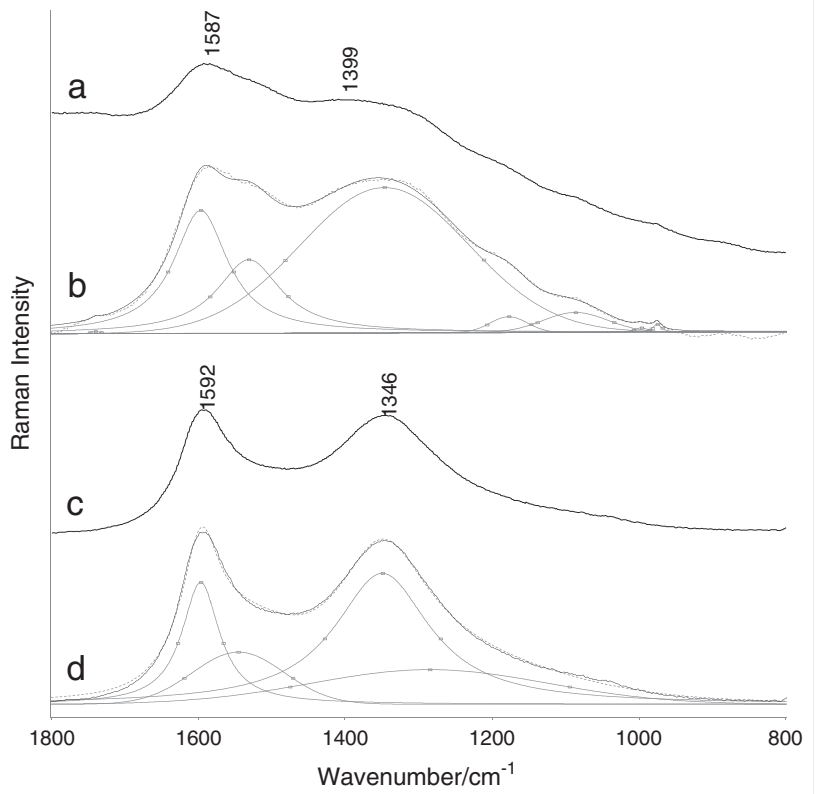

Figure 8. Raman spectra of flame carbons: bistre and furnace black, both green laser excited. a) bistre 532-nm laser, $1.4 \mathrm{~mW}, 100 \times 10 \mathrm{~s}$, b) bistre (baseline corrected, with deconvolution) $532-\mathrm{nm}$ laser, $1.4 \mathrm{~mW}, 100 \times 10 \mathrm{~s}$, c) furnace black $532-\mathrm{nm}$ laser, $1.4 \mathrm{~mW}, 300 \times 10 \mathrm{~s}$ and d) furnace black (baseline corrected, with deconvolution) $532-\mathrm{nm}$ laser, $1.4 \mathrm{~mW}, 300 \times 10 \mathrm{~s}$. 
Good quality spectra of the three fruitstone soots (Fig. 7) were recorded with the 785-nm laser, and all looked homogeneous: 1576$1587 \mathrm{~cm}^{-1}$ for the $\mathrm{G}^{*}$ band (average bandwidth of $85 \mathrm{~cm}^{-1}$ ) and for the disorder band it has to be mentioned that most of the time one extra band at ca. $1340 \mathrm{~cm}^{-1}$ was required for optimizing the fitting, in addition to the one at ca. $1311 \mathrm{~cm}^{-1}$.

The need for additional bands for deconvolution suggests a certain degree of disorder.

Furnace black and bistre (Fig. 8) were better excited with the 532$\mathrm{nm}$ laser, the first one having a flat background, the latter a very intense fluorescence signal. The $G^{*}$ band positions are 1593 and $1600 \mathrm{~cm}^{-1}$, respectively. The main disorder band of bistre is strongly shifting (1345 to $1397 \mathrm{~cm}^{-1}$, sometimes an extra band at ca. $1300 \mathrm{~cm}^{-1}$ was also needed), while furnace black required up to seven bands for the deconvolution of the range of 800 $1800 \mathrm{~cm}^{-1}$. Three of these bands fall in the region where the D1 band is expected $\left(1326,1377\right.$ and $\left.1378 \mathrm{~cm}^{-1}\right)$. Additional bands were needed at both edges of the deconvoluted region $\left(<1000 \mathrm{~cm}^{-1}\right.$ and $\left.>1700 \mathrm{~cm}^{-1}\right)$. The need of more bands than expected to deconvolute the disorder region is becoming more and more important when dealing with soots with respect to graphite and ordered carbons. As already mentioned, the more disorder,
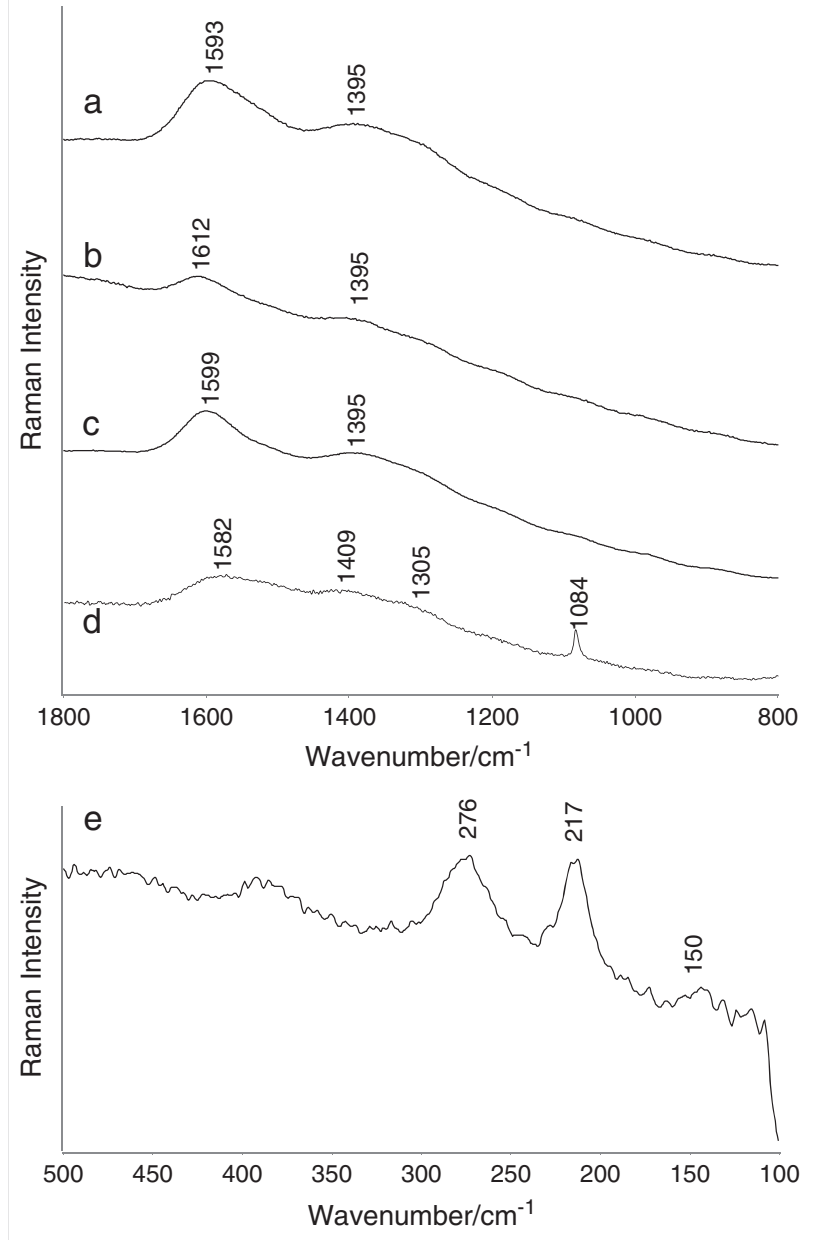

Figure 9. Raman spectra of humic earths/bituminous materials all collected with the green laser excitation. a) Van Dyck brown 532-nm laser, $1.4 \mathrm{~mW}, 30 \times 10 \mathrm{~s}$, b) Cassel earth $532-\mathrm{nm}$ laser, $0.17 \mathrm{~mW}, 30 \times 10 \mathrm{~s}, \mathrm{c}$ ) asphaltum $532-\mathrm{nm}$ laser, $1.4 \mathrm{~mW}, 60 \times 10 \mathrm{~s}$, d) atramentum 532 -nm laser, $1.4 \mathrm{~mW}, 30 \times 10 \mathrm{~s}$ and e) Van Dyck brown 532-nm laser, $1.4 \mathrm{~mW}, 30 \times 10 \mathrm{~s}$ (zoom in). the more Raman active bands can appear. ${ }^{[72]}$ Moreover, these two latter smoke carbons behave differently from the fruitstone ones, and also differently one from the other, probably in relation with the properties of the starting materials (wood for bistre, oil or bitumen for furnace black) or of the fabrication process (bistre is traditionally collected close to the flame which will give more tarry residues).

\section{Humic earths}

Both pigments Van Dyck brown and Cassel earth gave no results with the red excitation, and the 532-nm laser produced a high fluorescence background (Fig. 9). Weak, asymmetric bands are common to both pigments. No clear difference between them could be obtained by the producer's website (http://www.kremerpigmente.com/, last accessed 6/3/2015), mainly because the provided description is confusing: Van Dyck brown is described as a lignit coal from a mine near Cassel, Germany (and in the German website the pigment is named Kasslerbraun), while Cassel earth (Saftbraun in the German website) has no direct correlation with the mines near Cassel and is generally described as sodium salts of humic acids. The $\mathrm{G}^{*}$ band is asymmetric with a tail on the low wavenumber side. Its intensity maximum is relatively high (1606 $\left.\pm 10 \mathrm{~cm}^{-1}\right)$. The disorder band $\left(\mathrm{ca} .1390 \mathrm{~cm}^{-1}\right)$ is strongly asymmetric because of the overlap with a broad feature centred on $1300 \mathrm{~cm}^{-1}$, which is already visible in the raw spectrum. After baseline correction, it appears that the disorder feature has multiple shoulders on the low wavenumber side.

Iron oxides are reported among the constituents of Van Dyck brown. However, one single spectrum of Van Dyck brown showed additional bands in the low wavenumber region (212 and
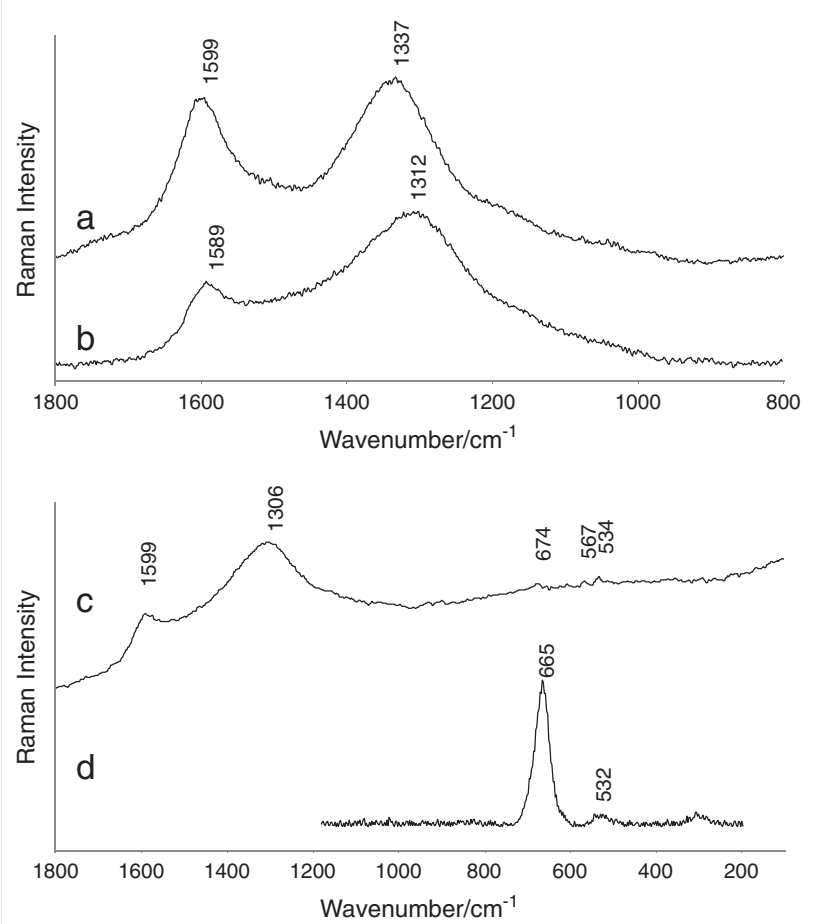

Figure 10. Other carbon-based black pigments Raman spectra: Sepia. a) Sepia average of 3 measurements $532-\mathrm{nm}$ laser, $1.4 \mathrm{~mW}, 10-40 \times 10 \mathrm{~s}, \mathrm{~b}$ ) sepia average of 3 measurements $785-\mathrm{nm}$ laser, $15.4 \mathrm{~mW}, 5-25 \times 20-35 \mathrm{~s}$, c) sepia (extended range) $785-\mathrm{nm}$ laser, $15.4 \mathrm{~mW}, 25 \times 30 \mathrm{~s}$ and d) magnetite R060656 (RRUFF database). 
Table 4. Positions of band maxima after baseline correction, observations on the fluorescence background and presence of additional bands in the spectra of the studied pigments. In bold are the data related to the $785-\mathrm{nm}$ excitation, in italic to $532 \mathrm{~nm}$.

\begin{tabular}{|c|c|c|c|c|c|}
\hline Carbon type & Pigment & $\underset{\left(\mathrm{cm}^{-1}\right)^{\mathrm{a}}}{\mathrm{G} \text { maximum }}$ & $\begin{array}{l}\text { D maximum } \\
\left(\mathrm{cm}^{-1}\right)^{\mathrm{a}}\end{array}$ & $\begin{array}{l}\text { Fluorescence } \\
\text { background }\end{array}$ & $\begin{array}{l}\text { Additional bands }\left(\mathrm{cm}^{-1}\right) \\
\text { disorder bands }(\text { carbon related } \\
\left.\text { — not assigned, } \mathrm{cm}^{-1}\right)\end{array}$ \\
\hline \multirow[t]{2}{*}{$\begin{array}{l}\text { Graphite and crystalline } \\
\text { carbons (see Figs. } 1 \text { and 4) }\end{array}$} & \multirow[t]{2}{*}{ Graphite } & $1593 \pm 4$ & $1308 \pm 3$ & $\begin{array}{l}\text { Flat, weak. Occasionally } \\
\text { intense. }\end{array}$ & 一; 1160, 1040 \\
\hline & & $1596 \pm 7$ & $1346 \pm 1$ & $\begin{array}{l}\text { Linear, intense but not } \\
\text { overwhelming. }\end{array}$ & $-; 1100$ \\
\hline $\begin{array}{l}\text { Graphite and crystalline } \\
\text { carbons (see Figs. } 1 \text { and 4) }\end{array}$ & Shungite & $1587 \pm 8$ & $1304 \pm 4$ & $\begin{array}{l}\text { Linear, weak; occasionally } \\
\text { intense. }\end{array}$ & $154,216,281,459 ; 1040$ \\
\hline \multirow[t]{2}{*}{$\begin{array}{l}\text { Graphite and crystalline } \\
\text { carbons (see Figs. } 1 \text { and 4) }\end{array}$} & \multirow[t]{2}{*}{ Black earth } & $1592 \pm 1$ & $1325 \pm 1$ & $\begin{array}{l}\text { Intense, almost } \\
\text { overwhelming. }\end{array}$ & 一; 1040, 910 \\
\hline & & $1602 \pm 3$ & $1350 \pm 5$ & Intense but not overwhelming. & $147,466,1086 ; 1330,1170,1080$ \\
\hline $\begin{array}{l}\text { Graphite and crystalline } \\
\text { carbons (see Fig. 4) }\end{array}$ & Black chalk & $1600 \pm 1$ & $1316 \pm 1$ & Linear, weak. & - \\
\hline \multirow[t]{2}{*}{$\begin{array}{l}\text { Coke of animal } \\
\text { origin (see Fig. 5) }\end{array}$} & \multirow[t]{2}{*}{ Ivory black } & $1583 \pm 3$ & $1315 \pm 5$ & $\begin{array}{l}\text { Intense but not } \\
\text { overwhelming. }\end{array}$ & 一; 1090, 910 \\
\hline & & $1594 \pm 5$ & $1329 \pm 1$ & $\begin{array}{l}\text { Very intense but not } \\
\text { overwhelming. }\end{array}$ & $\begin{array}{l}964,140 ; 3 \text { bands between } 1500 \text { and } \\
1300,1183,1090\end{array}$ \\
\hline $\begin{array}{l}\text { Coke of animal origin } \\
\text { (see Fig. 5) }\end{array}$ & Ivory black (pieces) & $1590 \pm 3$ & $1325 \pm 1$ & Linear, weak. & $一 ; 1300,1190$ \\
\hline Coke of animal origin & Bone black & $1587 \pm 2$ & $1314 \pm 2$ & Linear, weak. & 一; 1040, 920 \\
\hline $\begin{array}{l}\text { Chars of vegetal origin } \\
\text { (see Fig. 6) }\end{array}$ & Charcoal & $1583 \pm 6$ & $1326 \pm 5$ & $\begin{array}{l}\text { From weak to intense, not } \\
\text { overwhelming. }\end{array}$ & 一; 1310, 1030, 915 \\
\hline Flame carbons (see Fig. 8) & Furnace black & $1591 \pm 1$ & $1347 \pm 1$ & Flat. & $\begin{array}{l}\text { —; } 3 \text { bands between } 1380 \text { and } 1320 \\
1070\end{array}$ \\
\hline Flame carbons (see Fig. 7) & Peach black & $1583 \pm 2$ & $1313 \pm 1$ & $\begin{array}{l}\text { Strongly increasing towards } \\
\text { high wavenumber. }\end{array}$ & -; 1040, 920 \\
\hline Flame carbons (see Fig. 7) & Grape black & $1583 \pm 4$ & $1317 \pm 4$ & $\begin{array}{l}\text { Flat to intense, not } \\
\text { overwhelming. }\end{array}$ & 一; 1045, 920 \\
\hline Flame carbons (see Fig. 7) & Cherry black & $1581 \pm 5$ & $1317 \pm 1$ & $\begin{array}{l}\text { Flat to intense, not } \\
\text { overwhelming. }\end{array}$ & 一; 1050, 920 \\
\hline Flame carbons (see Fig. 8) & Bistre & $1587 \pm 4$ & $1361 \pm 5$ & Intense. & $174,295,1096 ; 1180,1090,980$ \\
\hline Flame carbons (see Fig. 9) & Atramentum & $\begin{array}{c}1565 \pm \\
1561 \pm 4\end{array}$ & $\begin{array}{l}1315 \pm \\
1410 \pm 10\end{array}$ & $\begin{array}{l}\text { Intense. } \\
\text { Intense. }\end{array}$ & $\begin{array}{l}\mathbf{2 7 2}, \mathbf{3 6 0}, \mathbf{1 0 8 3} ; \mathbf{1 4 1 0}, \mathbf{1 0 8 0}, 920 \\
144,258,706,1026,1083 ; 1360,1080\end{array}$ \\
\hline Flame carbons (see Fig. 9) & Asphaltum & $1597 \pm 2$ & $1375 \pm 4$ & Intense. & 140,$107 ; 1180,1090$ \\
\hline Humic earths (see Fig. 9) & Van Dyck brown & $1593 \pm 3$ & $1379 \pm 1$ & Intense, flat. & 214,$274 ; 1180,1090,980$ \\
\hline Humic earths (see Fig. 9) & Cassel brown & $1603 \pm 1$ & $1381 \pm 1$ & Intense, flat. & 143,$108 ; 1195,1085,980$ \\
\hline Others (see Fig. 10) & Sepia & $1588 \pm 1$ & $1304 \pm 1$ & Linear. & 535,$674 ; 1400$ \\
\hline & & $1597 \pm 3$ & $1340 \pm 5$ & Linear, weak. & 276,1509 \\
\hline
\end{tabular}

$272 \mathrm{~cm}^{-1}$, see Fig. 9, spectrum e). Seen the effect of laser power on hematite (in this case $1.4 \mathrm{~mW}$ ), these bands could be assigned to hematite. ${ }^{[83]}$

Asphaltum was also measured with the green laser, and the obtained spectra are extremely similar to those of Van Dyck brown and Cassel earth. The similarity (bitumen rich coals) among all these three materials is also observed in their Raman spectra, which show an intense fluorescence background, broad $\mathrm{G}^{*}$ band and a shoulder centred around $1300 \mathrm{~cm}^{-1}$, which strongly modifies the symmetry of the D1 band.

Atramentum is a particularly confusing pigment, as this name could refer to iron salts of tannic acids, soot or even ivory black (Table 2). The spectrum of our product resembles the ones of humic earths as van Dyck brown and Cassel earth, with strongly asymmetric bands, but here the Raman band of calcite is clearly visible, at $1084 \mathrm{~cm}^{-1}$ (Fig. 9, ${ }^{[75,76]}$ ).

\section{Sepia}

The dry black ink produced by cuttlefish was tested with both lasers. In addition to the expected bands of carbon, other features appear. The band maxima in the raw spectrum are at ca. 1590 and ca. $1305 \mathrm{~cm}^{-1}$ for the red excitation and at ca. 1600 and ca. $1340 \mathrm{~cm}^{-1}$ for the green one. In the spectra recorded with the 785-nm excitation some broad, weak bands at 535, 566 and $674 \mathrm{~cm}^{-1}$ are visible (Fig. 10, spectra $a$ and b). The comparison of our spectra with the few available published data ${ }^{[84,85]}$ is not giving clear conclusions. Anyway, one of the spectra of Sepia showed additional bands (see Fig. 10, spectra $\mathrm{c}$ and d) that can be assigned to the black iron based pigment magnetite $\mathrm{Fe}_{3} \mathrm{O}_{4}$. The band at $665 \mathrm{~cm}^{-1}$ is related to magnetite, even if this band can be found in the range of $662-670 \mathrm{~cm}^{-1[83]}$ and even up to $706 \mathrm{~cm}^{-1}$. ${ }^{[86]}$ Also the band at $534 \mathrm{~cm}^{-1}$ is reported in literature 
for magnetite. ${ }^{[83,86]} \mathrm{A}$ band at ca. $570 \mathrm{~cm}^{-1}$ is reported in literature to appear in Fe(III) doped Sepia. ${ }^{[84]}$

The presence of a black iron phase could be eventually related to a modification of the intact Sepia pigment, as Fe(III)-enriched Sepia melanin shows the appearance of bands at 570 and $1470 \mathrm{~cm}^{-1}$. ${ }^{[84]}$ The first one was here detected, while the second one is overlapping with the carbon features. Moreover, the Sepia band at $460 \mathrm{~cm}^{-1}$ disappears with increasing iron content, and here is not observed, which supports the hypothesis of Fe(III)-enriched Sepia.

It is clear that the raw spectra of carbonaceous black pigments are hard to evaluate as they are. However, some useful guidelines for discriminating among the different classes of carbonaceous pigments can be put forward.

The Raman spectrum of carbonaceous pigments, as obtained after baseline subtraction, seems more promising. At this point, it is also possible to investigate the fine structure of the Raman spectrum through deconvolution with Gaussian and/or Lorentzian curves. Such an approach is essential especially when dealing with disordered carbons, which show additional bands, and of increasing intensity with respect to ordered materials. ${ }^{[33]}$

The expected downshift of the D1 and $G^{*}$ bands with increasing laser wavelength was observed in those samples measured with both lasers, which gave clear Raman spectra with both excitations, for example graphite (Fig. 2).

Table 4 summarizes some features of the recorded Raman spectra. No information is given there about the bandwidth, as both the $\mathrm{G}$ and $\mathrm{D}$ bands are asymmetric and require from 2 to 4 components for deconvolution. It is interesting to note the presence of additional bands. Some are related to minerals that are present as impurities (quartz, calcite, etc.) while some others required a more detailed investigation.

For most of the investigated carbon-based black pigments, the combination of $\mathrm{G}$ and $\mathrm{D} 2$ bands is expected, which affects the spectral parameters (position, bandwidth, intensity and area) of the $\mathrm{G}^{*}$ band. It is then difficult to use the $G^{*}$ band spectral parameters in correlations, especially if they are supposed to coincide with the $\mathrm{G}$ band parameters.

As already mentioned, a broad band was always present in the studied set of samples with a maximum between 1300 and $1400 \mathrm{~cm}^{-1}$. Different degrees of symmetry and shoulders were observable, because the disorder features of carbon (and artefacts bands related to the baseline correction, if any) all fall in this range. The so called D1 band is extremely sensitive to a variety of factors and shifts strongly, actually across the whole disorder range 1240 to $1400 \mathrm{~cm}^{-1 \cdot[3,33,49]}$ Whenever supplementary disorder-related features arise, the correct identification of the D1 band becomes extremely difficult (see Fig. 9). On the higher wavenumber side of the D1 band, the D3 band is found, which corresponds to impurities and has a Gaussian profile. On the lower wavenumber side, the overlap is with the D4 band, which is only described for soot samples. Moreover, additional bands at ca. 1150 and below $1100 \mathrm{~cm}^{-1}$ have been described in literature but no clear explanation and assignment is found among the scientific community. The lower recorded band position is $1040 \mathrm{~cm}^{-1}$ for the red excited spectra and $1093 \mathrm{~cm}^{-1}$ for those excited with the green laser. Again, the use of the D1 band's spectral parameters for correlations seems questionable in the case of strongly disordered materials, because of overlapping and shifting features.

In general, the red laser worked well for all the materials except those richer in tarry, bituminous materials (furnace black, Atramentum, bistre, Van Dyck brown, Cassel earth and Asphaltum), which were more effectively excited with the 532-nm laser.
The possibility of clearly resolving the $\mathrm{D} 2$ band from the $G$ points out a higher degree of order, which is found in black chalk and ivory black in pieces (red laser) and in black earth and ivory black, when measured with the green laser. Additional bands to the expected $G$ and D1-D4 are found, especially towards lower wavenumbers, in disordered carbons (see Table 4). These bands are still not assigned, but their presence can help in distinguishing among different carbon blacks.

The possibility of using the obtained set of data for direct chemometric discrimination for unknown samples seems complicated by different reasons. Authors generally do not focus onto standardized approach and sampling and obtaining spectroscopic data. Careful comparison of the shape of the $G$ and $D$ bands can especially be recommended as well as estimation of FWMH. New method for discrimination of carbons of different origins and crystallinities using Raman spectroscopy is currently to be tested in our labs.

\section{Conclusions}

Carbonaceous materials are currently investigated for geological and industrial applications: the materials and analytical techniques involved in this specific literature partially overlap with the archaeometrists' interest. In this paper we have presented Raman spectra obtained on carbon-based black pigments references, trying to better understand their characteristics and to establish a procedure for discrimination among different carbon-blacks on the basis of their spectral parameters.

The application of Raman spectroscopy to the study of carbonbased black pigments is a challenging topic for many reasons. The results here presented are intended to provide some references (see Table 3), in terms of Raman spectra and of terminology, to those dealing with works of art. Also, some guidelines based on the Raman signature of carbonaceous reference materials are provided to help in the identification of unknown carbon-based black pigments. The widespread use of the definition 'carbon-black' for the whole range of carbon-based black pigments seems reductive, especially when considering the potentiality of Raman analysis, as demonstrated by its applications to the geological field.

The Raman spectra of carbonaceous materials suffer from the effect of the excitation wavelength and other experimental parameter, as well as of the data processing. Moreover, the fluorescence background associated with binding media used in works of art can affect the successful identification of the used pigment, as the linear baseline correction might be inapplicable.

For the purpose of archaeometrical research, anyway, the use of Raman spectroscopy can give a deeper insight in the material history of works of art, and can help in clarifying which type of carbon-black was used; always keeping in mind the complex nature of carbonbased black pigments with respect to geological definitions.

\section{Acknowledgements}

The authors wish to thank Ghent University for its financial support through the Concerted Research Action 'Archaeometrical Study of the Ghent Altarpiece'.

\section{References}

[1] B. B. Berrie, Artists' Pigments, Archetype Publications, London, 2007.

[2] L. Rampazzi, L. Campo, F. Cariati, G. Tanda, M. P. Colombini, Archaeometry 2007, 49(3), 559. 
[3] E. Tomasini, G. Siracusano, M. S. Maier, Microchem. J. 2012, 102, 28.

[4] M. Olivares, K. Castro, M. S. Corchon, D. Garate, X. Murelaga, A. Sarmiento, N. Etxebarria, J. Archaeol. Sci. 2013, 40, 1354.

[5] E. Chalmin, M. Menu, C. Vignaud, Meas. Sci. Technol. 2003, 14, 1590.

[6] F. D'Errico, South African Archaeol. Soc. Goodwin Ser. 2008, 10, 168.

[7] R. J. Gettens, G. L. Stout, Painting Materials, Dover Publications, New York, 1966.

[8] F. Ospitali, T. Sabetta, F. Tullini, M. C. Nannetti, G. Di Lonardo, J. Raman Spectrosc. 2005, 36(1), 18.

[9] K. Castro, M. Perez-Alonso, M. D. Rodriguez-Laso, N. Etxebarria, J. M. Madariaga, Anal. Bioanal. Chem. 2007, 387, 847.

[10] M. Menu, P. Walter, Nucl. Instrum. Methods Phys. Res. 1992, B64, 547.

[11] A. Zoppi, G. F. Signorini, F. Lucarelli, L. Bachechi, J. Cult. Heritage 2002, 3, 299.

[12] G. M. Languri, Molecular Studies of Asphalt, Mummy and Kassel Earth Pigments: Their Characterization, Identification and Effect on the Drying of Traditional oil Paint, Archetype publications, London, 2004.

[13] F. Ospitali, D. C. Smith, M. Lorblanchet, J. Raman Spectrosc. 2006, 37, 1063.

[14] J. Striova, C. Lofrumento, A. Zoppi, E. M. Castellucci, J. Raman Spectrosc. 2006, 37, 1139

[15] J. Van der Weerd, G. D. Smith, S. Firth, R. J. Clark, J. Archaeol. Sci. 2004, 31 (10), 1429.

[16] G. Giachi, E. De Carolis, P. Pallecchi, Mater. Manuf. Processes 2009, 24, 1015.

[17] L. C. Prinsloo, W. Barnard, I. Meiklejohn, K. Hall, J. Raman Spectrosc. 2008, 39, 646.

[18] H. G. M. Edwards, P. S. Middleton, S. E. Jorge Villar, D. L. A. de Faria, Anal. Chim. Acta 2003, 484, 211.

[19] H. G. M. Edwards, S. E. Jorge Villar, K. A. Eremin, J. Raman Spectrosc. 2004, 35, 786.

[20] M. C. Caggiani, P. Colomban, J. Raman Spectrosc. 2011, 42, 839.

[21] D. V. Thompson Jr, The Craftsman's Handbook 'll Libro dell' Arte' by Cennino d'A. Cennini, Yale University Press, New Haven, 1933.

[22] N. Eastaugh, V. Walsh, T. Chaplin, R. Siddall, Pigment Compendium, Elsevier Butterworth-Heinemann, Burlington, Massachussets, 2004

[23] E. P. Tomasini, E. B. Halac, M. Reinoso, E. J. Di Liscia, M. S. Maier, J. Raman Spectrosc. 2012, 43(11), 1671.

[24] J. Winter, Stud. Conserv. 1983, 28(2), 49.

[25] N. Mironova-Ulmane, A. Kuzmin, M. Grube, J. Alloys Compd. 2009, 480, 97.

[26] N. Buzgar, A. I. Apopei, A. Buzatu, J. Archaeol. Sci. 2013, 40, 2128.

[27] M. Spring, R. Grout, R. White, Natl. Gallery Tech. Bull. 2003, 24, 96.

[28] K. Trentelman, N. Turner, J. Raman Spectrosc. 2009, 40, 577.

[29] E. Buzzegoli, C. Castelli, C. Giovannini, D. Kunzelman, M. Parri, P. Petrone, A. Ramat, A. Santacesaria, O. Sartiani, Fra Bartolomeo e la scuola di San Marco, Marsilio Editore, Venice, 1996, pp. 293-313.

[30] E. Buzzegoli, D. Kunzelman, C. Giovannini, G. Lanterna, F. Petrone, A. Ramat, O. Sartiani, P. Moioli, C. Seccaroni, Art et chimie, la couleur: actes du congress, (CNRS Editions, Paris), Paris, 2000, pp. 203-208.

[31] C. P. Marshall, R. W. Fairbridge, Encyclopedia of Geochemistry, Kluwer Academic Publishers, Dordrecht, 1999.

[32] D. W. van Krevelen, Coal: Typology, Chemistry, Physics, Constitution, Elsevier, Amsterdam, 1984.

[33] E. V. Ulyanova, A. N. Molchanov, I. Y. Prokhorov, V. G. Grinyov, Int. J. Coal Geol. 2014, 121, 37.

[34] J. N. Rouzaud, A. Oberlin, Carbon 1989, $27,517$.

[35] M. S. Dresselhaus, G. Dresselhaus, in Light Scattering in Solids III (Eds.: M. Cardona, G. Guntherodt), Springer, Berlin, 1982, p. 187.

[36] A. Oberlin, Carbon 1984, 22, 521.

[37] Y. Wang, D. C. Alsmeyer, R. L. McCreery, Chem. Mater. 1990, $2,557$.

[38] J. Jehlicka, O. Frank, J. Pokorny, J.-N. Rouzaud, Spectrochim. Acta, Part A 2005, 61, 2364.

[39] M. S. Dresselhaus, G. Dresselhaus, R. Saito, A. Jorio, Phys. Rep. 2005, 409, 47.

[40] F. Tuinstra, J. L. Koenig, J. Chem. Phys. 1970, 53(3), 1126.

[41] R. P. Vidano, D. B. Fischbach, L. J. Willis, T. M. Loehr, Solid State Commun. 1981, 39(2), 341.

[42] J. D. Pasteris, B. Wopenka, Can. Mineral. 1991, $29,1$.

[43] O. Beyssac, B. Goffé, C. Chopin, J.-N. Rouzaud, J. Metamorph. Geol. 2002, 20,859 .
[44] C. L. Angell, I. C. Lewis, Carbon 1978, 16(6), 431.

[45] N. K. Lunsdorf, I. Dunkl, B. C. Schmidt, G. Rantitsch, H. von Eynatten, Geostand. Geoanal. Res. 2014, 38(1), 73.

[46] A. Olcott Marshall, C. P. Marshall, Astrobiology 2013, 13(9), 814.

[47] B. Dippel, J. Heintzenberg, J. Aerosol Sci. 2000, 30(1), S907.

[48] S. Fonti, A. Blanco, E. Bussoletti, L. Colangeli, M. Lugara, V. Mennella, V. Orofino, G. Scamarcio. Infrared Phys. 1990, 30(1), 19.

[49] M. Yoshikawa, G. Katagiri, H. Ishida, A. Ishitani, T. Akamatsu, J. Appl. Phys. 1988, 64(11), 6464

[50] L. Nikiel, P. W. Jagodzinski, Carbon 1993, 31(8), 1313.

[51] A. Sadezky, H. Muckenhuber, H. Grothe, R. Niessner, U. Pöschl, Carbon 2005, 43, 1731.

[52] J. Jehlicka, O. Urban, J. Pokorny, Spectrochim. Acta, Part A 2003, 59, 2341.

[53] C. Sheng, Fuel 2007, 86, 2316.

[54] O. Beyssac, B. Goffé, J.-P. Petitet, E. Froigneux, M. Moreau, J.-N. Rouzaud, Spectrochim. Acta, Part A 2002, 59, 2267.

[55] A. Cuesta, P. Dhamelincourt, J. Laureyns, A. Martínez-Alonso, J. M. D. Tascón, Carbon 1994, 32(8), 1523.

[56] O. Urban, J. Jehlicka, J. Pokorny, J. N. Rouzaud, Spectrochim. Acta, Part A 2003, 59, 2331.

[57] A. C. Ferrari, J. Robertson, Phys. Rev. B 2001, 63, R-121405.

[58] B. Dippel, H. Jander, J. Heintzenberg, Phys. Chem. Chem. Phys. 1999, 1 , 4707.

[59] K. Ishimaru, T. Hata, P. Bronsveld, T. Nishizawa, Y. Imamura, J. Wood Sci. 2007, 53, 442

[60] K. Ishimaru, T. Hata, P. Bronsveld, D. Meier, Y. Imamura, J. Mater. Sci. 2007, 42, 122

[61] S. Yamauchi, Y. Kurimoto, J. Wood Sci. 2003, 49, 235.

[62] J. Bostock, The Natural History. Pliny the Elder, M.D., F.R.S. H.T. Riley, Esq., B.A. Taylor and Francis, London, 1855.

[63] M. Bouchard, D. C. Smith, Spectrochim. Acta, Part A 2003, 59, 2247.

[64] P. D. Green, C. A. Johnson, K. M. Thomas, Fuel 1983, 62(9), 1013.

[65] R. Tsu, J. H. González, C. I. Hernández, Solid State Commun. 1978, 27(5), 507.

[66] K. Angoni, Carbon 1993, 31(4), 537.

[67] G. Gouadec, P. Colomban, Prog. Cryst. Growth Charact. Mater. 2007, 53 (1), 1.

[68] S. Bernard, O. Beyssac, K. Benzerara, N. Findling, G. Tzvetkov, G. E. Brown Jr, Carbon 2010, 48, 2506.

[69] M. R. Ammar, J.-N. Rouzaud, J. Raman Spectrosc. 2012, 43, 207.

[70] S. Potgieter-Vermaak, N. Maledi, N. Wagner, J. H. P. Van Heerden, R. Van Gieken, J. H. Potgieter, J. Raman Spectrosc. 2011, 42, 123.

[71] T. W. Zerda, A. John, K. Chmura, Fuel 1981, 60(5), 375.

[72] M. Nakamizo, R. Kammereck, P. L. Walker Jr, Carbon 1974, 12, 259.

[73] D. S. Bethune, G. Meijer, W. C. Tang, H. J. Rosen, W. G. Golden, H. Seki, C. A. Brown, M. S. de Vries, Chem. Phys. Lett. 1991, 179, 181.

[74] K. Castro, M. Pérez-Alonso, M. D. Rodríguez-Laso, L. A. Fernández, J. M. Madariaga, Anal. Bioanal. Chem. 2005, 382, 248.

[75] R. T. Downs, Program and Abstracts of the 19th General Meeting of the International Mineralogical Association in Kobe, Japan, 2006.

[76] L. Burgio, R. J. H. Clark, Spectrochim. Acta, Part A 2001, 57, 1491.

[77] I. M. Bell, R. J. H. Clark, P. J. Gibbs, Spectrochim. Acta, Part A 1997, 53, 2159.

[78] H. G. M. Edwards, E. M. Newton, J. Russ, J. Mol. Struct. 2000, 550, 245.

[79] M. Perez-Alonso, K. Castro, J. M. Madariaga, Anal. Chim. Acta 2006, 571, 121.

[80] G. D. Smith, R. J. H. Clark, J. Archaeol. Sci. 2004, 31, 1137.

[81] H. G. M. Edwards, D. W. Farwell, C. J. Brooke, Anal. Bioanal. Chem. 2005, $383,312$.

[82] J. Ambers, J. Raman Spectrosc. 2004, 35, 768.

[83] D. L. A. de Faria, S. V. Silva, M. T. de Oliveira, J. Raman Spectrosc. 1997, $28,873$.

[84] A. Samokhvalov, Y. Liu, J. D. Simon, Photochem. Photobiol. 2004, $80,84$.

[85] S. A. Centeno, J. Shamir, J. Mol. Struct. 2008, 873, 149.

[86] O. N. Shebanova, P. Lazor, J. Solid State Chem. 2003, 174, 424 